\title{
An analysis of the welding-induced deformation of ship panels using a statistical tool
}

\author{
Huggo S. Batista, M.Sc., \\ Tadeusz Graczyk, Assoc. Prof., \\ West Pomeranian University of Technology, Szczecin
}

\begin{abstract}
This paper proposes a practical way to predict the welding-induced deformation of 5-mm-thick steel ship panels prefabricated in a Polish shipyard, developed by means of a number of experiments and a body of data collected on the butt welding line using the submerged arc welding technique. The program of the experiments was so designed as to test different welding energy conditions as well as pressure values generated by the devices used during the welding. Subsequently, different welding trials were carefully carried out and data collected to find the most important parameters which contribute to welding deformation. The data obtained were analysed using the Design-Expert ${ }^{\circledR}$ statistical software, and consideration was given to the data arrangement method that would allow for the most appropriate description of the welding deformation. As a result of the foregoing efforts, an approach to predicting the welding deformation, based on a numerical equation including the main welding parameters, was developed. The accuracy of the equation was partially evaluated and the results turned out to be satisfactory, as the actual and the predicted values were comparable. Another important advantage achieved was the arrangement of data used to compute the welding deformation.
\end{abstract}

Keywords: ship production technology; welding deformation; design of experiment; statistics

\section{INTRODUCTION}

Analysing the contemporary ship production requires some attention on issues related to design of ships, the capacity of shipyards and work stations, as well as production technology due to the fact that business factor is related to them. In consequence these subjects are in permanent development because of their significance for the production costs besides, schedule and quality. Consequently, there is a need in the shipbuilding industry for improvements to shorten delays and avoiding rework due to quality problem or even creating new solutions for the production processes.

The following issues are examples of possible improvements in the ship production technology:

- development of new raw materials that can be used in the shipbuilding industry;

- reduction of rework related to deformations occurring after welding (straightening processes);

- reduction of the time required to prepare cut outs in steel parts;

- development of technologies for fitting parts to be welded (section assembling);

- way to mitigate the welding induced deformation (steel plates).
A computational simulation might aid researchers in planning changes in the shipyard without physical modifications, although other types of experiments will have to be performed so that to verify the actual results, as well. Because of this certain improvements demands practical trials to verify the actual results before the modification implemented.

Looking forward to reduce the process timing, material waste, labour used and, consequently, waste of money, shipyards and design offices involve in wide-scale cooperation. For that reason, over the years researchers have implemented new ideas and carrying out various experiments in shipyards. This work is an example of that, showing a practical way to analyze the deformation in the ship panel after welding in the shipyard. Other examples of this kind of work can be found in [2], where a methodology allowing for the prediction of welding distortions and prevention of rework caused by, for instance, straightening, is presented. This way of thinking is also confirmed in the work [1], where experiments were used to understand the effects of welding on the structure, and in the work [7], which describes investigations of the weld geometry effects on the mechanical properties of undermatched welds.

Generally, steel welding is the source of one of the most fundamental problems in the shipbuilding industry, as it leads to the deformation of steel parts due to residual stresses resulting 
from the interaction between welding parameters and the geometry of steel parts. Therefore this work aims at verifying a numerical way to predict the welding induced deformation after submerged arc welding during the normal production in the shipyard.

\section{WELDING PROCESSES IN THE SHIPBUILDING INDUSTRY}

According to [4], fusion welding can be described as a joining process which uses the base metal molten by high temperature to join elements.

The welding process has been used in many different types of industries due to:

- the reliability of the structures assembled;

- high speeds in mass production;

- the possibility to use automated robots to perform the welding;

- efficiency in constructing standardized parts through the use of automation;

- high quality.

Welding processes have disadvantages, as well, some of which are listed below:

- complex quality control processes;

- the need for skilled operators;

- expensive and complex infrastructure when automated welding processes are implemented;

- the possibility of substantial hazards and losses in the event a failure of the welded part during its life (the steel structures of civil buildings, vessels, oil rigs or motor vehicles).

In order to avoid these disadvantages the welding technology needs special care about the process control.

In shipbuilding, welding is extensively used because of the significant demand for steel or aluminium alloys to be used in structural elements, such as ship hulls, watertight bulkheads, decks, bottom, being typically all-welded thin plate structures, [3]. Therefore, during fabrication some deformations may occur that are caused by several factors, including the cutting of the plates and pieces, or the welding of the joints between them.

There are several methods for connecting parts. Before commencing joining works, some issues must be considered:

- the type of joint to be made;

- the type of material to be welded;

- the limitations of the production layout;

- the thickness of the plates;

- the purpose of the welding.

Submerged Arc Welding (SAW) is widely used in the shipbuilding industry and, according to [7], it offers high productivity. It is a mechanized welding method that can make use of a single electrode or several ones at the same time. The electric arc burns underneath a layer of protective flux which melts in the vicinity of the arc and produces solid slag on the weld. The non-molten excessive flux is reused.

\section{A Few Characteristics}

To arrange the welding procedure and to get reasonable results this is necessary to understand a few characteristics and effects influencing the work pieces which will be welded. Some of them have been commented earlier, such as: the type of the welding process or workpiece geometry. However, other issues are equally important when the welding process is under evaluation.
From this point of view, the following aspects should be treated as equally significant:

\section{Heat input}

Heat input can be described as one of the most important factors involved in welding and, according to [8], a significant variable related to the quality of welding, mainly with regard to the warping problem identified in welded products. Heat input affects the dimensions of the welded object, as it brings enough energy to melt the additional material and the workpiece. Such energy may generate local deformation, as indicated in [3]. Heat input is the relation between the welding energy used during the operation and the speed of the welding source along the process. This relation is measured in units of energy (Joules) per units of length $(\mathrm{mm}$ or $\mathrm{cm})$. Together they are helpful in determining the amount of heat which will be applied to the metal in order to melt the base material (workpiece) and the fusible wire (additional material).

\section{Residual Stress}

The heat that is necessary to melt metal parts in order to join them reaches extremely high temperatures, inevitably causing certain physical phenomena inside the workpiece due to the difference between the molten pool temperature and the room one. As a consequence of this, some characteristics of the particular element may be affected due to the quick heating and cooling cycle that occurs during welding.

\section{Welding deformation}

Deformations generated during the welding process are strongly linked to the residual stress, and for many researchers they are an unavoidable problem present in every welding work. In the shipyards, according to [4] and [6], the most representative problem is the one of misalignment between blocks during the hull erection stage. These problems occur due to deformations caused by welding, which in turn cause inaccuracies in entire blocks and structural member misadjustment. These authors also claim that welding deformations do not only interfere with the aesthetical aspect, but also put the structural integrity of the ship at risk when in service.

Hence, all these characteristics must be known during the welding process to minimize the problems once the ship is delivered.

\section{MODELLING}

The literature provides a multitude of methods developed over the years using the most diversified tools designed to identify, understand, correct or, at least, mitigate the undesirable effects that the aforementioned problem has on the workflow and other production aspects. Taking advantage of some of them may help eliminate certain inconveniences encountered in the workflow which, in turn, will improve the efficiency of the process.

In order to counter these welding problems, FEM is usually used to simulate and investigate residual stress distribution along the geometry, and subsequently to suggest modifications to improve the process.

For the same reason, statistical tools are used in the process analysis, especially to solve problems or even process management. This approach drives the research toward the understanding of the process, once a number of trials are necessary to be performed. In addition, this can lead to a better insight into the current situation, which may help minimize the unfavourable effects or increase the production capacity.

The purpose of the experiments is to explain the process through its behaviours based on the actual results which are acquired from the process. The trials need to be carefully modelled, contemplating the major of the variables that take part in the analysis to know all effects of those variables in the 
process. It means that all of the characteristics of the process should be evaluated in order to make sure that no inaccurate results are obtained.

It is very important to know which factors exist within the process that have a tangible effect on the final output. From the point of view of analysis, these are factors that contribute to the occurrence of the problem. To illustrate this, only a few of the various relevant factors are mentioned below regarding to the welding induced deformation:

- welding energy (current and voltage);

- welding speed;

- welding type;

- the thickness of the plates;

- the boundary conditions during the welding process.

In this case, experiments and evaluations were carried out during the normal production in the shipyard following the design of experiment (DoE) methodology.

\section{Defining the Problem}

According to [5], a number of experiments were carried out in Polish shipyard aiming at the prediction and mitigation of the welding-induced deformation which occurs after the butt-welding of $5 \mathrm{~mm}$ thick plates using SAW. The trials were developed on the stiffened panels with the following dimensions: width of $12 \mathrm{~m}$ and length of 10 or $12 \mathrm{~m}$. These panels were used on the deck or in bottom area. These panels usually consist of 4 or 5 plates (depending on the length of the panel) and consequently 3 or 4 weld seams (12 m long). The plates were laid on the SAW work line to be joined by the weld seam, once their edges were already prepared.

In this case, when the panels lay properly and flat on the welding line, the causes of such deformations were sought. Certain conclusions were drawn from the analyses and the shipyard staff came up with the idea to verify the welding gantry facilities used to perform butt welding on the first side of the panels.

Fig. 1a provides a general view of the magnetic bed and the copper bar used for butt welding the first side of the panels. Fig. $1 \mathrm{~b}$ is a simple diagram showing the forces (arrows) affecting the plates during welding. A Design of Experiment needed to be carried in order to figure out the effects of the welding parameters adding to the effect of the pressure induced by the copper bar and the magnetic bed. The first plate was positioned on the right side of the magnetic bed and then aligned along the edge and clamped by the magnetic blocks. The second plate was pulled towards the first edge plate until the span between them was around 0 to $5 \mathrm{~mm}$, after this the second plate was also clamped by the magnetic blocks from the left side (Fig. 1b). Once properly positioned, the manual tack welding was performed by the operator, afterwards the operator puts down the tack welding using the pneumatic countersink. From this condition, the copper bar acted on the plate junction (I-profile) and then was possible to perform the first side butt welding using the SAW gantry.

The copper bar has been used on SAW processes to guarantee that the molten material will not leak between the plates during the process, besides it works as ground for the electric procedure and holds the 2 plates at the correct position to perform the weld.

The magnetic bed was used to fix the plates before welding and its working parameters were previously defined together with the experienced shipyard staff. The pressures were set up directly on the pressure board according to the values determined to be used during the trails ( $\mathrm{DoE}-$ see Tab. 1.)

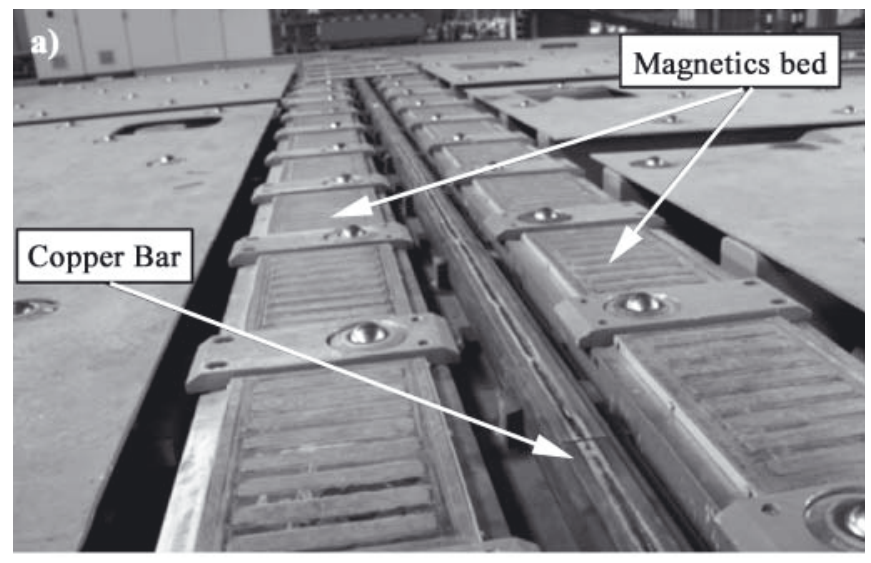

b)

\section{Copper Bar}

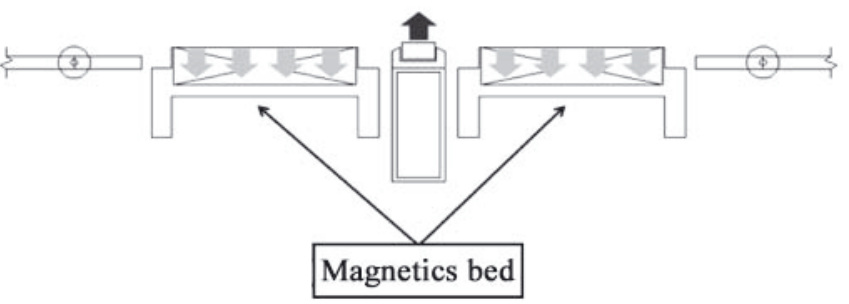

Fig. 1. The welding gantry

\section{Data Processing}

The first idea for arranging the data was to evaluate the mean value for related points distributed along the entire panel. However, this plan was discarded due to the fact that each panel had 3 different weld seams connecting its plates. The deformation should be investigated by examining each weld seam with the intention of narrowing down the number of sources of errors caused by external factors, and even excluding initial plate deformation. Thus, concentrating the measurement on areas near the weld seam could help to mitigate negative influence from these factors.

Hence, a number of approaches were examined. On the one hand, we examined the mean value of deformation between points related to the weld seam and, on the other hand, the largest value of deformation on the way from the centre of the plate to the weld seam.

Based on these examinations, two methods for data arrangement were analysed, as explained below:

- Option 1 - Mean value arrangement

This option is illustrated in Fig. 2 showing the diagram adopted for the purposes of obtaining the value. To facilitate the analysis, this arrangement will hereinafter be referred to simply as "Option 1".

This diagram consists of the mean value between two points (in the middle of the plate) neighbouring on a point on the weld seam.

$$
\begin{aligned}
\mathrm{D}_{\mathrm{Op}_{-} \mathrm{1}_{\mathrm{i}, \mathrm{j}}}= & \left|\frac{\mathrm{P}_{(\mathrm{i}+3)+6 \cdot(\mathrm{j}-1)}+\mathrm{P}_{(\mathrm{i}+9)+6 \cdot(\mathrm{j}-1)}}{2}-\mathrm{P}_{(\mathrm{i}+6)+6 \cdot(\mathrm{j}-1)}\right|(1) \\
& \mathrm{D}_{\mathrm{Op} \__{-}\left(\operatorname{seam}_{\mathrm{j}}\right)}=\operatorname{Max}\left(\mathrm{D}_{\mathrm{Op}_{-} 1_{\mathrm{i}, \mathrm{j}}}\right) \\
& \text { with i varying from } 1 \text { to } 3
\end{aligned}
$$

Where:

$\mathrm{j}$
- characterizes the weld seam. This number varies from 1 to 3 ; 


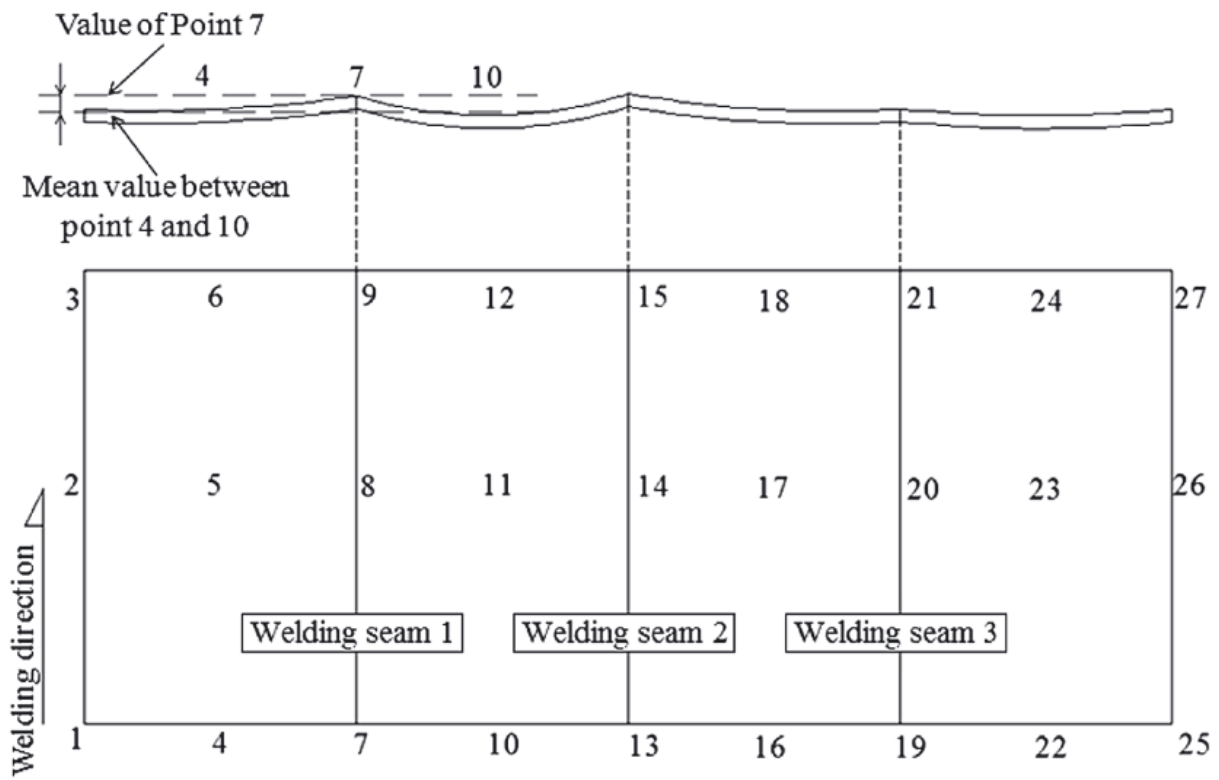

Fig. 2. Mean value arrangement: Option 1

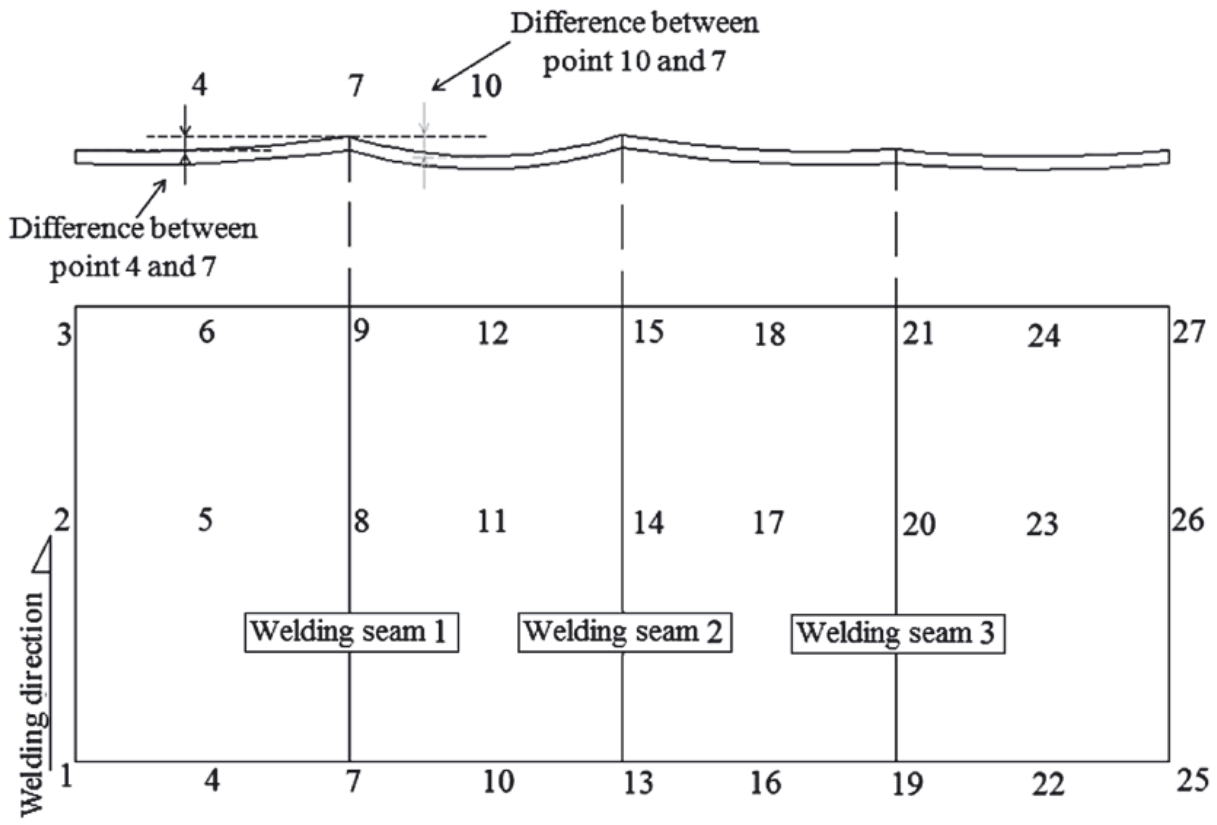

Fig. 3. Largest value arrangement: Option 2

i - the value which determines the position of the deformation along the weld seam. This number varies from 1 to 3 ;

$\mathrm{P}_{\mathrm{x}} \quad-$ the value measured in $\mathrm{mm}$ at point $x$;

$\mathrm{x} \quad-$ the index of point $\mathrm{P}$. This number varies from 4 to 24 ;

$\mathrm{D}_{\mathrm{Op} \_} \mathrm{l}_{\mathrm{i}, \mathrm{j}} \quad$ - the deformation calculated at weld seam $\mathrm{j}$ at point i;

$\mathrm{D}_{\text {Op_1 }\left(\text { seam }_{\mathrm{j}}\right)}$ - the largest value among the three $\mathrm{D}_{\mathrm{Op} \_\mathrm{l}_{\mathrm{i}}}$ values calculated at weld seam $\mathrm{j}$. In other words, it is 1 out of 3 values of deformation analysed during the data processing;

Adopting this point of view, it is possible to realize that: each weld seam has three different $\mathrm{D}_{\mathrm{Op} \_\mathrm{i}_{\mathrm{i}}, \mathrm{v}}$ values (one for each edge and another one for the centre of the plate;

- the largest value among the three values measured is considered as an amplitude on the current weld seam $\mathrm{D}_{\mathrm{Op} 1 \text { (seam.; }}$;

- consequently, each panel yields three values for data processing.
Option 2 - the largest value

Fig. 3 illustrates the arrangement that takes into account the largest value of deformation around each weld seam. Similarly to Option 1, this arrangement will hereinafter be referred to as "Option 2", simply to make the analysis easier.

This diagram makes use of the largest value of the difference between individual points neighbouring on the weld seam.

$$
\begin{gathered}
\mathrm{D}_{\mathrm{Op}_{-} 2_{\mathrm{i}, \mathrm{j}}}=\operatorname{Max}\left(\left|\mathrm{P}_{(\mathrm{i}+3)+6 \cdot(\mathrm{j}-1)}-\mathrm{P}_{(\mathrm{i}+6)+6 \cdot(\mathrm{j}-1)}\right|,\right. \\
\left.\left|\mathrm{P}_{(\mathrm{i}+9)+6 \cdot(\mathrm{j}-1)}-\mathrm{P}_{(\mathrm{i}+6)+6 \cdot(\mathrm{j}-1)}\right|\right) \\
\mathrm{D}_{\mathrm{Op} \__{-} 2\left(\operatorname{seam}_{\mathrm{j}}\right)}=\frac{1}{3} \sum_{\mathrm{i}=1}^{3}\left(\mathrm{D}_{\mathrm{Op} \_2_{\mathrm{i}, \mathrm{j}}}\right)
\end{gathered}
$$

Where:

j $\quad-$ characterizes the weld seam. This number varies from 1 to 3 ; 
i $\quad-$ the value which determines the position of the deformation along the weld seam. This number varies from 1 to 3 ;

$\mathrm{P}_{\mathrm{x}} \quad-$ the value measured in $\mathrm{mm}$ at point $x$;

$\mathrm{x} \quad-$ the index of point $\mathrm{P}$. This number varies from 4 to 24 ;

$\mathrm{D}_{\mathrm{Op} \_2_{\mathrm{i}, \mathrm{j}}} \quad-$ the deformation calculated at weld seam $\mathrm{j}$ at point $\mathrm{i}$;

$\mathrm{D}_{\mathrm{Op} \_2\left(\operatorname{seam}_{\mathrm{j}}\right)}-$ the largest value among the three $\mathrm{D}_{\mathrm{Op} \_2_{\mathrm{i} j}}$ values calculated at weld seam $\mathrm{j}$. In other words, it is 1 out of 3 values of deformation analysed during the data processing;
Adopting this methodology, it is also possible to realize that:

- each weld seam also has three different values (one for each edge and another one for the centre of the plate;

- the average value among the three values measured is considered as an amplitude on the weld seam;

- consequently, each panel yields three values for data processing.

Once the arrangement is defined, the values for plate deformation used during the data processing are showed in Tab. 1.

Tab. 1. Deformation values from two data arrangements

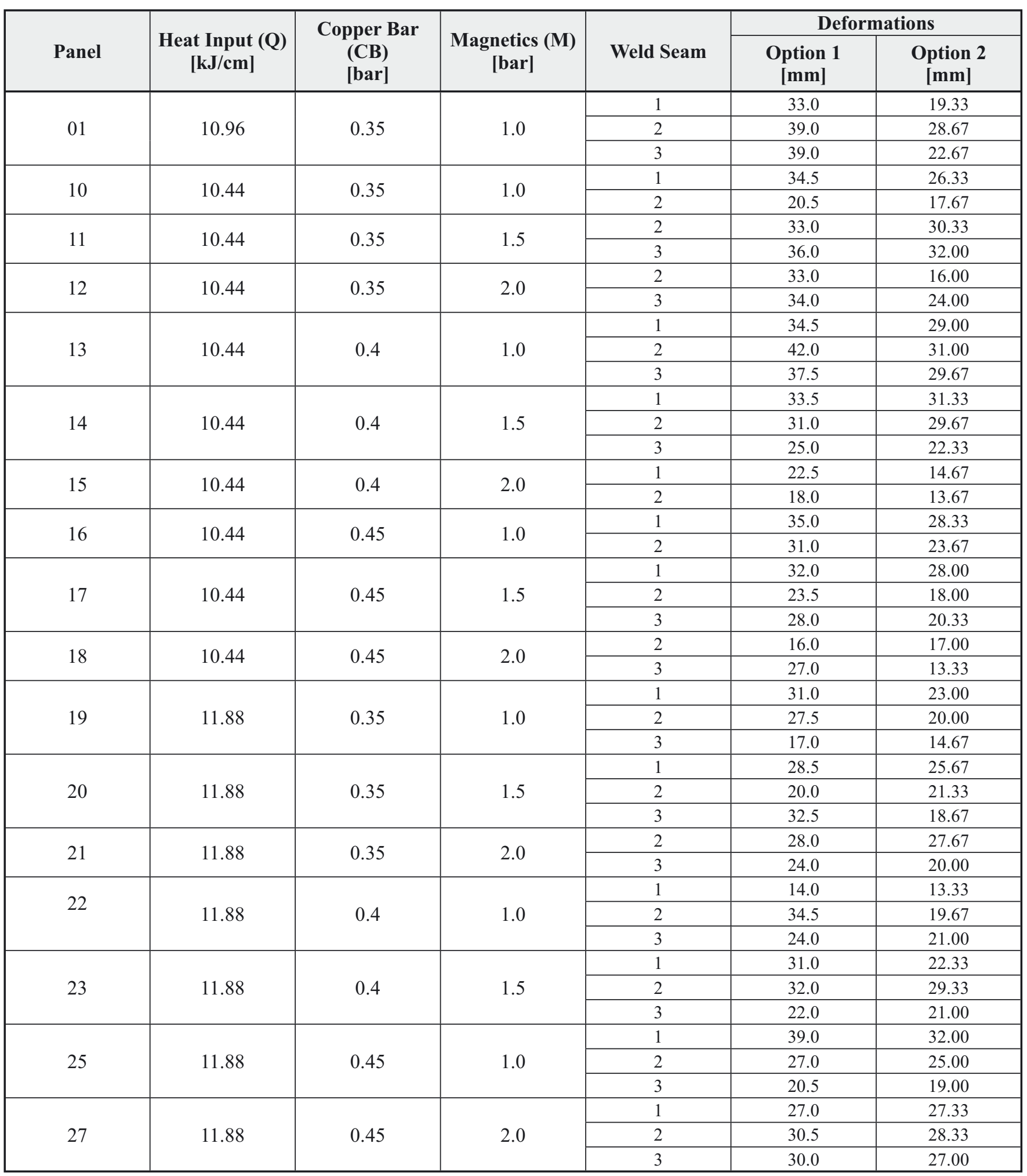




\section{RESULTS AND DISCUSSION}

Aided by the statistical software to compile the results obtained from the experiment, the values used generated two numerical equations. These equations make it possible to verify the results and the accuracy of each value provided by the models, by comparing it to the actual value of deformation measured on the steel ship panel in the shipyard. All the variables were considered by the software, including the data arrangement (see Fig. 2 and Fig. 3), to get these 2 final equations and a number of consideration were taken into account to choose the models. These considerations are described below.

For boundary conditions, the values for copper bar pressure, magnetic pressure and heat input (according to Table 1) were considered as well as the data arrangement to build the DoE (according to Figure 2 and Figure 3). The values from the plate edge were not considered and only real data (measured along the plate, according to the Figure 2 and 3 ) were inputted to get the equation to predict the welding deformation.

The numerical equations are presented below:

- Option 1 - Mean value arrangement

$$
\mathrm{D}_{\mathrm{Op}_{1}}=185.70-13.49 \cdot \mathrm{Q}-90.69 \cdot \mathrm{M}+7.74 \cdot \mathrm{Q} \cdot \mathrm{M}
$$

- Option 2 - Largest value arrangement

$$
\begin{aligned}
& \mathrm{D}_{\mathrm{Op}_{2}}=422.45-35.87 \cdot \mathrm{Q}-574.08 \cdot \mathrm{CB}+ \\
& -113.80 \cdot \mathrm{M}+52.41 \cdot \mathrm{Q} \cdot \mathrm{CB}+10.01 \cdot \mathrm{Q} \cdot \mathrm{M}
\end{aligned}
$$

The values obtained from Option 1 demonstrate a standard deviation of approx. $6.1 \mathrm{~mm}$, while the values obtained from Option 2 demonstrate a standard deviation of approx. 4.7. This difference exists because the data arrangements are different from each other. Therefore, an obvious consequence of that is that Option 1 presents a larger range of differences in deformation values than the one provided by Option 2 in trials illustrated in Tab. 2:

Tab. 2. A comparison between the results from Option 1 and Option 2

\begin{tabular}{|c|c|c|c|}
\hline Option & Limits & $\begin{array}{c}\text { Values } \\
{[\mathbf{m m}]}\end{array}$ & $\begin{array}{c}\text { Amplitude of the } \\
\text { differences in } \\
\text { deformation values } \\
{[\mathbf{m m}]}\end{array}$ \\
\hline \multirow{2}{*}{1} & Maximum & 14.52 & 26.76 \\
\cline { 2 - 3 } & Minimum & -12.26 & \multirow{2}{*}{20.29} \\
\hline \multirow{2}{*}{2} & Maximum & 11.62 & \multicolumn{2}{|c|}{20} \\
\cline { 2 - 3 } & Minimum & -8.67 & \multicolumn{2}{|c|}{} \\
\hline
\end{tabular}

A graphical comparison of these values is better at visualising the difference between the models.

Fig. 4 (a) and (b) show that although the points are not fully distributed on the $45^{\circ}$ straight line (which would be the ideal condition for the values predicted), they are concordant to a certain extent with the actual values. It is also obvious that the manner in which the points are laid down in Option 2 is

a)

Predicted vs. Actual



b)

Predicted vs. Actual

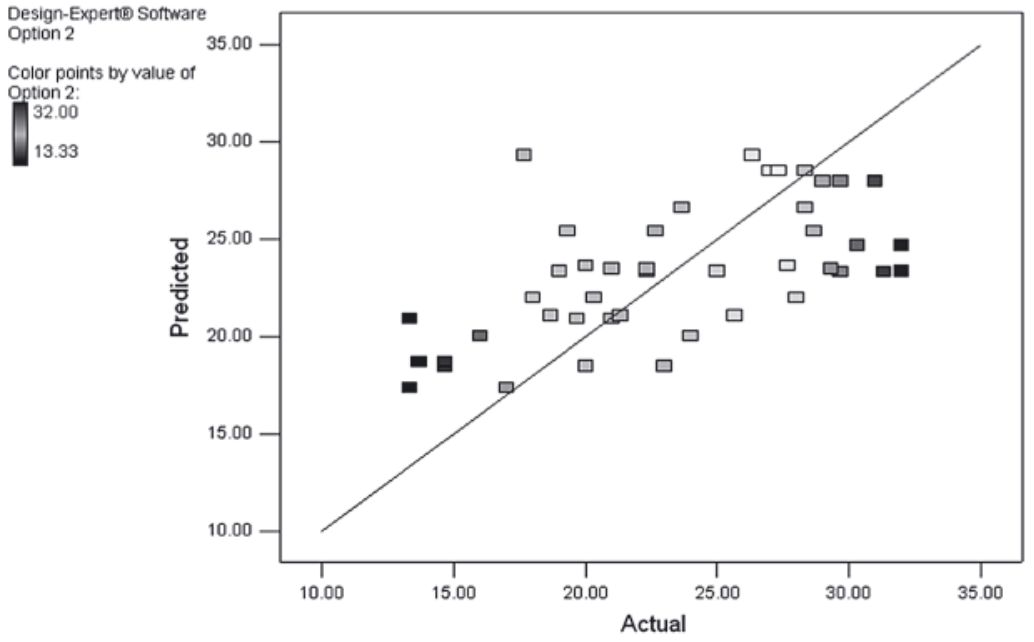

Fig. 4. A comparison between the actual and the predicted deformation values: a) Option 1 and b) Option 2 
superior to the shape created in Option 1 . This particularly refers to the points located at the extremities of the curve (the larger and smaller values obtained in the arrangement). In Option 2, they are spread along the line, whereas the points in Option 1 are concentrated near the mean values.

Another method for verifying the predicted deformation values for both the cases studied is shown in Fig. 5 .

The cube chart makes it possible to verify all the predicted deformation values across the entire spectrum of the variability of the main factors. Highlighted in Fig. 5 (a) and (b) are the maximum (the black rectangle) and minimum (the grey rectangle) results for the deformation predicted for both the models. The best condition for work (i.e. the condition which renders the lowest deformation values according to those models) is with the following values: heat input $=10.44 \mathrm{~kJ} / \mathrm{cm}$, copper bar pressure $=0.45 \mathrm{bar}$, magnetic pressure $=2 \mathrm{bar}$.

According to these results, Option 2 demonstrates better results than Option 1 due to the smaller amplitude of the residual variation.

After the results of these two options were verified from the statistical and dimensional points of view, it was confirmed that the model described by Option 2 yielded better outcome than the one described by Option 1. There are a number of reasons that justify these results, one of them being leaving out the copper bar effects of the model.

Moreover, another aspect of the approach adopted in this paper is the fact that the models developed through the DoE account for the average of the input values, i.e. the models operate based on the average deformation between the weld seam values. If we compare the predicted values to the average values of the weld seam the standard deviation becomes smaller, which in turn means that the model is capable of properly reflecting most of the results.

Therefore, for future evaluations using this methodology, it would be reasonable to evaluate the welding deformation of $5 \mathrm{~mm}$ thick steel plates.

\section{SUMMARY}

After the work done in the shipyard, the numerous trials performed on the panel welding line, the measurements taken and the result analyses carried out, a number of interesting conclusions can be drawn from the investigation, which can be formulated as follows:

1. Unlike the main methodology making use FEM simulation as proposed by several authors, the welding deformation in
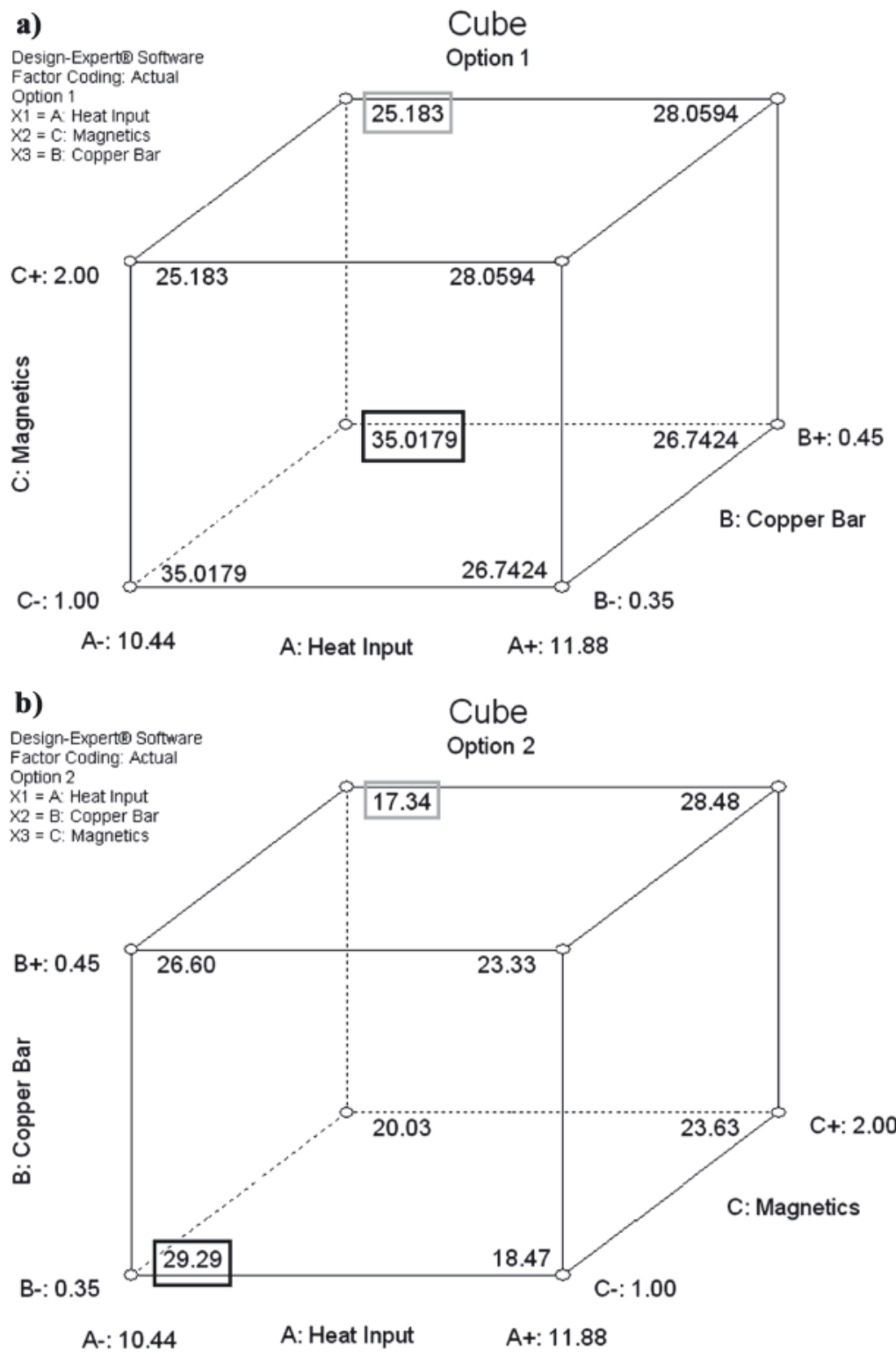

Fig. 5. Predicted deformation values: a) Option 1 and b) Option 2 
butt joints on $5 \mathrm{~mm}$ thick steel plates can also be predicted by a statistical method, as shown in this paper.

2. An analysis subject to statistical principles may yield different results depending on how the data are inputted, and this characteristic became an important issue encountered in the course of this paper. Because of this, specific data arrangements were chosen and their results verified with the intention to derive a numerical equation capable of predicting, with the highest accuracy possible, the values of deformation similar to the ones measured in the shipyard. Surprisingly, from each data arrangement a different equation could be derived and, sometimes, such an equation did not take into account the influence of the all of the factors present.

3. The numerical equation obtained from the statistical software, through the data arrangement described by Option 2, rendered reasonable results, as compared to the data collected in the shipyard. Therefore, it can be considered a satisfactory method for predicting the weldinginduced deformation in $5 \mathrm{~mm}$ thick steel panels.

It is also worth noting that all kinds of experiments, especially those performed under strict conditions dependent on time and equipment availability, are subject to the influence of the existing sources of errors. Such sources should be identified and, whenever possible, avoided. For future projects related to analyses through experiments, the following recommendations should be taken into account:

1. Measurements: the same person, the same equipment and the same conditions should be used to perform the measurements.

2. Feedback: throughout the task, there is a need for intensive communication with the workers responsible for the process to make sure they have sufficient understanding of the experiment. These workers will be in charge of the quality control; therefore, if during the trials something goes wrong they will be able to introduce the required corrections and fix the problems as they occur.

3. Feedback: similarly, the key person (tasked with rendering assistance whenever necessary) must be identified before the start of the experiment.

4. Noise in the model: verification of the initial condition (deformation) of the plates before the commencement of the welding process. It can help the researcher to sort the noise out of data processing, improving the overall results.

A few of the aforementioned errors may have some minor influence on the final results presented. However, the methodology used was developed taking as careful measures as possible to ensure its reliability.

A number of extra trials should be performed in order to verify the actual accuracy of the model.

\section{BIBLIOGRAPHY}

1. Awang M.: The effects of process parameters on steel welding response in curved plates. Thesis of Master of Science in Mechanical Engineering. West Virginia University. 2002.

2. Birk-Srrrensen M.: Simulation of welding distortions in ship section. Industrial $\mathrm{PhD}$ Thesis. Technical University of Denmark. 1999.

3. Deng D., Murakawa H., Ueda Y.: Theoretical Prediction of Welding Distortion Considering Positioning and the Gap between Parts. 2002. The Proceedings of the Twelfth International offshore and polar engineering conference. Accessed 17 November 2011,

4. Kou S.: Welding metallurgy. 2nd ed. USA: John Wiley \& Sons, Inc. 2003.

5. Sena Batista H.: Analysis and prediction of welding deformations of ship panels in prefabrication process. Master Thesis for the double degree: "Advanced Master in Naval Architecture" conferred by University of Liege "Master of Sciences in Applied Mechanics, specialization in Hydrodynamics, Energetics and Propulsion" conferred by Ecole Centrale de Nantes, work developed at West Pomeranian University of Technology, Szczecin in the framework of the "EMSHIP" Erasmus Mundus Master Course in "Integrated Advanced Ship Design”. Ref. 159652-1-2009-1-BE-ERA MUNDUS-EMMC. 2011.

6. Sukovoy O., Kuo C.: a risk-based method for minimizing welding distortion in steel ship production. Engineering for the Maritime Environment, 217 (3), 123-131. 2003.

7. Törnblom S.: Undermatching Butt Welds in High Strength Steel. Master Thesis. Luleí University of Technology. 2007.

8. Tsai C. L., Park S. C., Cheng W. T.: Welding Distortion of a Thin-Plate Panel Structure [online]. American Welding Society. 1999. Accessed 12 December 2011.

\section{CONTACT WITH THE AUTHORS}

$$
\begin{aligned}
& \text { Huggo S. Batista, M.Sc., } \\
& \text { huggosena@gmail.com } \\
& \text { +5592 } 88049416 \\
& \text { Tadeusz Graczyk, Assoc. Prof., } \\
& \text { tadeusz.graczyk@zut.edu.pl } \\
& \text { +48 } 914494696
\end{aligned}
$$

Faculty of Maritime Technology and Transportation West Pomeranian University of Technology, Szczecin 70-310 Szczecin, Al. Piastów 17, POLAND 